\title{
A Construção do Processo Democrático de Auto-Avaliação Institutucional na Unesp
}

\author{
Sonia Maria Duarte Grego ${ }^{1}$, Sheila Zambello de Pinho², \\ José Reinaldo Cerqueira Bráz ${ }^{3}$, Eunice Oba ${ }^{4}$, \\ Hélia Sonia Raphael ${ }^{5}$, Maria Cristina Fumie Iwana Matos ${ }^{6}$
}

Recebido: 21/03/07

Avaliado: 25/05/07

\begin{abstract}
Resumo: O desenvolvimento de um processo democrático de avaliação institucional na UNESP, uma universidade multi-campus, envolveu três desafios: garantir o envolvimento de grupos representativos da comunidade no processo de avaliação; atribuir poder e responsabilidade a cada setor acadêmico e administrativo no processo de avaliação; criar uma cultura de auto-avaliação e reflexão que possibilitasse debate crítico e auto-gestão dos projetos acadêmicos. Com base nos termos de referência estabelecidos pela comunidade a CPA desenvolveu uma metodologia de avaliação democrática e investigativa, orientada para a auto-gestão e de natureza quali-quantitativa. Fundamentada em três enfoques teóricos de avaliação, o democrático, o de tomada de decisão e o crítico o processo envolveu três funções: a diagnóstica, a formativo-reflexiva e a de revisão crítica. Atualmente os usos dos resultados da avaliação para orientar políticas e decisões acadêmicas, especialmente nos cursos de graduação, evidenciam avanços no processo de internalização de cultura de avaliação orientada para auto-gestão.
\end{abstract}

Palavras-chaves: avaliação institucional formativa, avaliação democrática, autonomia, auto-gestão, grupo de estudo em avaliação.

\section{Developing a democratic institutional evaluation process at UNESP}

\begin{abstract}
The challenge of developing and implementing a democratic process of institutional evaluation at UNESP (São Paulo State University), a multi-campus university, was threefold: to guarantee the involvement of representative reference groups in the process of evaluation; to empower and assign responsibility in the evaluative process to each academic and administrative sector and; to create a culture of self-evaluation and reflection which would enable critical and informed debates and self-management of academic projects. Based on references and objectives established by the community, a self-regulative and quali-quantitative oriented democratic and investigative evaluation methodology was developed. Based on three theoretical evaluation approaches: decision making, democratic and critical, the process involved three roles: diagnostic, formative reflexive and critical revision. To this moment, the use of the evaluation results to enlighten policies and academic decisions, especially in undergraduate programs, shows improvement in the process of internalizing a democratic and self-regulative culture of evaluation.
\end{abstract}

Key words: formative institutional evaluation; democratic evaluation; autonomy; self-regulative culture; evaluation studies group.

\footnotetext{
${ }^{1}$ Profa. Adjunto do Depto. de Didática e do Programa de Pós-Graduação em Educação Escolar da UNESP - Araraquara. Coord. do Grupo de Pesquisa em Avaliação e Políticas Educacionais - UNESP. Ex-membro da CPA - UNESP. E-mail: smdgrego@vivax.com.br

${ }^{2}$ Pró-Reitora de Graduação e Ex-membro da CPA - UNESP. E-mail: sheila@ $@$ reitoria.unesp.br
} 
Na virada do século, no ano de 2000, em um cenário de avaliação da educação superior autoritária e centralizada sob a iniciativa do Governo Federal, o Conselho Estadual de Educação do Estado de São Paulo (CEESP) assume a responsabilidade de regular e avaliar seu sistema universitário, apresentando uma proposta alternativa e divergente, centrada em um processo de auto-avaliação institucional. Sob iniciativa do CEESP as universidades paulistas são instadas a se responsabilizarem pela elaboração e implementação de um projeto de auto-avaliação institucional, incluindo a avaliação externa, a apresentarem um relatório parcial ao final de três anos e um relatório final, após cinco anos, contendo deliberações dos órgãos colegiados sobre ações a serem realizadas para superação dos problemas evidenciados na avaliação.

Essa nova sistemática de avaliação institucional representou para as universidades paulistas "a possibilidade de construção de processos democráticos de auto-avaliação, alicerçados nos princípios de autonomia e liberdade acadêmica, e de construção de uma cultura avaliativa orientada para a auto-gestão." (GREGO, 2005, p. 115)

$\mathrm{Na}$ UNESP, apesar de experiência anterior de envolvimento em processo de auto-avaliação como participante do PAIUB, três grandes desafios tiveram de ser enfrentados para desenvolvimento e implementação de um processo democrático de avaliação orientado para a auto-gestão: garantir participação representativa dos grupos de referência na definição dos princípios, objetos, critérios e usos da avaliação; dar poder aos grupos acadêmicos, tornando-os co-partícipes e responsáveis pelo seu próprio processo de avaliação; e criar uma cultura de auto-avaliação e auto-reflexão que possibilitasse um debate crítico e informado sobre os programas e projetos acadêmicos e o uso dos resultados para informar o processo de tomada de decisões em todas as instâncias.

A avaliação de contexto realizada na fase de elaboração do projeto identificou como um dos principais problemas o impacto do sistema de avaliação da educação superior do Governo Federal vigente na época, considerando que sua influência acirrava divergências e conflitos de interesses e valores em questões acadêmicas e em perspectivas de avaliação a

\footnotetext{
${ }^{3}$ Prof. Titular do Depto. de Anestesiologia e Ex-Presidente da Comissão Permanente de Avaliação da UNESP. E-mail: jbraz@fmb.unesp.br

${ }^{4}$ Profa. Titular do Depto. de Reprodução Animal e Radiologia Veterinária. Ex-Coord. da Comissão de Especialistas da CPA - UNESP. E-mail- euniceoba@fmvz.unesp.br

${ }^{5}$ Docente do Curso de Pedagogia e do Programa de Pós-Graduação em Educação da UNESP Marília e ex-membro da Comissão de Especialistas da CPA - UNESP.E-mail: hsonia@ flash.tv.br ${ }^{6}$ Profa. Dra. do Depto. de Patologia da Faculdade de Medicina da UNESP - Botucatu. Especialista em Educação Médica pela Universidade de Dundee. Ex-membro da Comissão de Especialistas da CPA-UNESP - E-mail: cristinamattosconsult@gmail.com
} 
serem privilegiadas. A análise desse contexto possibilitou a identificação de focos de tensão e de mecanismos e procedimentos para superá-los, viabilizando a construção de um processo de auto-avaliação institucional na UNESP. Considerando que com a implantação do SINAES (Sistema Nacional de Avaliação da Educação Superior) pelo Governo Federal, em 2004, a auto-avaliação institucional ganha centralidade no interior das Instituições de Educação Superior, a discussão desses focos de tensão e do processo de construção da auto-avaliação institucional na UNESP em uma perspectiva democrática e orientada para a auto-gestão, objetiva contribuir para a qualificação do debate sobre o papel e o potencial da autoavaliação como instrumento chave na efetiva avaliação da educação superior no Brasil.

\section{O Contexto da Avaliação da Educação Superior no início do século XXI}

A partir da década de 1980 ganharam centralidade os processos de avaliação e regulação da educação superior (NEAVE; VAN VUGT, 1994), que se ampliaram a partir da década de 1990, alimentados pela convergência histórica da globalização, das economias orientadas para o conhecimento e pelo reconhecimento crescente do papel fundamental da educação terciária como fator "de acumulação do capital humano e de crescimento econômico" (OCDE, 2002, p. 5).

Foi também na década de 1980 que a questão da avaliação como instrumento de controle da educação superior por parte do Estado Brasileiro apareceu pela primeira vez no Relatório de uma Comissão de alto nível, nomeada pelo Presidente da República: a Comissão Nacional para a Reformulação da Educação Superior. (BRASIL, 1985)

No entanto, foi só com a publicação do Relatório GERES - Grupo Executivo para a Reformulação da Educação Superior (BRASIL, 1986), indicado para operacionalizar as idéias propostas pela comissão anterior, que ocorreu o maior impacto. Ao propor uma nova política, estabelecendo a avaliação para o credenciamento e recredenciamento das instituições de ensino superior, este documento gerou intensos debates entre universidades e Governo em torno de questões conceituais e teórico-metodológicas. Essas questões, não superadas até hoje, dividem posições, sustentam resistências e continuam a apresentar desafios às Comissões de Avaliação Interna das Universidades no desenvolvimento de estratégias que articulem negociação política com sólidos e transparentes princípios teóricos. 
Em especial, dois focos de tensão, claramente identificados nesse primeiro debate nacional, vêm se mantendo como pontos centrais de conflito em relação às propostas de avaliação que se sucedem no Brasil. Desvelá-los quanto às formas e conteúdos que têm assumido historicamente tem-se tornado condição primordial para o avanço da teoria e da prática da avaliação e para a o estabelecimento de uma cultura avaliativa no interior das instituições universitárias.

O primeiro foco diz respeito às funções e usos da avaliação. Revelase "na tensão entre a expectativa do sistema político de que as universidades dêem conta dos serviços prestados à sociedade e do uso do dinheiro público - avaliação com função de controle político, com base em indicadores quantitativos e comparáveis - e a expectativa da comunidade universitária por formas de avaliação mais democráticas" (GREGO, 1995, p. 29) - avaliação com função formativa e participativa, capaz de subsidiar processos de auto-reflexão e transformação dos projetos e programas institucionais.

A questão de qual é a missão da universidade em um determinado momento histórico constitui o segundo foco de tensão.

Na perspectiva do Governo Central a educação superior e, em conseqüência, sua avaliação têm se mantido fortemente ligadas a interesses econômicos e/ou políticos e sofrem, ainda, a influência de uma política restritiva do pólo público-estatal e de valorização do pólo público-mercantil, que levou à expansão do setor privado, que detém hoje 71,7\% das matrículas na educação superior. (BRASIL, 2005)

Posição diversa, centrada em uma avaliação democrática e participativa, tem sido defendida pelo setor público universitário. Nessa posição a avaliação é assumida como um organizador qualificado que traz implícito o compromisso social com a garantia de padrões de excelência na formação e na produção de conhecimentos; com a ampliação das oportunidades de acesso a todos que possam se beneficiar do ensino superior; com a formação de consciência crítica e com a melhoria das condições de vida da sociedade. (GREGO, 1995; MOROSINI, LEITE, 1997; DIAS SOBRINHO, 2004)

Esses diferentes entendimentos sobre a função da universidade têm levado a um conflito entre diferentes concepções de qualidade acadêmicoinstitucional, que se faz presente na polêmica sobre as concepções e modelos de avaliação da produção acadêmica e, em especial, sobre os indicadores e critérios utilizados para estimá-las.

Nesse quadro de disputas conceituais e ideológicas, a posição das universidades públicas logrou alguns avanços ao longo dos anos 1980 até 
meados dos anos 1990, com a implantação de programas de avaliação subsidiados pelo Governo Federal como o PAIUB (Programa de Avaliação Institucional das Universidades Brasileiras), envolvendo processos de autoavaliação das instituições de educação superior por adesão voluntária. Nesse momento a UNESP aderiu ao PAIUB, definindo-se pela adoção de uma proposta de avaliação institucional democrática e orientada para a autogestão.

No entanto, os principais problemas para uma implementação bem sucedida de um processo de auto-avaliação, em geral a ausência de uma cultura de avaliação institucional democrática e a falta de familiaridade com a teoria e a prática da avaliação educacional no interior da academia, não foram superados, considerando que em meados de 1990 esse programa foi descontinuado e o controle da avaliação passou para as mãos do governo. De fato, a partir de 1997, sob a pressão do "Estado Avaliador", a avaliação da educação superior torna-se um mecanismo de regulação, um instrumento de reforma política e de controle da qualidade da educação superior como uma base para o ranqueamento das instituições, extensivamente reforçado por lei.

Os elementos centrais do sistema de avaliação nacional tornam-se o Exame Nacional de Cursos, que avalia o desempenho dos estudantes, e a Análise das Condições de Ensino, diretamente relacionada com resultados e orientada para o mercado.

A prevalência dos indicadores e critérios impostos pelo governo teve impacto de longo alcance em toda comunidade acadêmica e na dinâmica institucional, estimulando uma variedade de respostas e reações nos diferentes grupos acadêmicos, muitas vezes diametralmente opostas, em relação às avaliações tanto internas como externas.

O Conselho de Reitores das Universidades Brasileiras (CRUB), opondo-se à sistemática do governo, tornou pública, em 2001, uma proposta de avaliação que expressava a posição da comunidade acadêmica, em defesa de "quatro princípios que deveriam ser considerados em um processo de avaliação: credibilidade, legitimidade, transparência e participação." (CRUB, 2001, p. 7).

Alguns grupos acadêmicos envidaram esforços para adiantar-se na condução de processos de auto-avaliação institucional, por sua própria iniciativa, por considerá-los apropriados ao desenvolvimento institucional e os únicos a garantirem a legitimidade do processo no julgamento da qualidade da educação superior. Dentre esses, lograram maior sucesso os ini- 
cialmente filiados ao PAIUB. Muitas dessas experiências, no entanto, têm procedido com dificuldades ou foram descontinuadas, seja pela ausência de vontade política, por conflitos de interesses internos, por questões de natureza metodológica e/ou pela ausência de uma cultura positiva de avaliação institucional orientada para a tomada de decisões.

Outros grupos acadêmicos têm mantido uma posição política contra a avaliação institucional seja interna ou externa. Esses grupos defendem que há já uma grande quantidade de processos avaliativos na educação superior, recusando-se, dessa forma, a legitimar os processos de avaliação e as competências dos avaliadores tanto dos grupos locais como do poder central, bem como os referenciais, critérios e indicadores estabelecidos pela instituição ou pelo governo. Esses grupos mantêm, em geral, uma posição em defesa do sistema de mérito acadêmico, como já identificado por Kogan (1993).

Progressivamente, no entanto, muitos grupos acadêmicos têm evidenciado um comprometimento em aceitar e acatar, incondicionalmente, os padrões e indicadores da avaliação externa estabelecida pelo governo, resistindo, dessa forma, a participar efetivamente dos processos de construção de indicadores internos, mesmo quando esse exercício interno é requerido pelo próprio governo central ao qual se subordinam. Pode-se mesmo observar, em alguns casos, um privilegiamento pelos docentes, dentre as atividades relacionadas à missão da Universidade, por atividades mais valorizadas segundo os critérios do governo, como pesquisa e publicações.

A despeito dessas posições divergentes, a questão central no início desse século não era, no entanto, se deveria ou não haver avaliação, mas quem deveria conduzi-la e com base em que referencial ela deveria ser realizada. O que se contrapunha, no ano em que se iniciava o novo século, era a determinação do governo em estabelecer unilateralmente a sistemática e os critérios de avaliação e a aspiração da comunidade acadêmica de efetiva participação no processo e de poder para julgar a qualidade de seus próprios programas e projetos.

Foi nesse contexto que o Conselho de Educação do Estado de São Paulo apresentou uma proposta alternativa para avaliação do seu Sistema Universitário, tornando oficial um paradigma de avaliação institucional que privilegia o processo de avaliação interna das universidades, como elemento básico de referência para os processos externos de avaliação da qualidade da educação superior. (SÃO PAULO, 2000) 


\section{Uma política de avaliação alternativa para o Sistema Universitário do Estado de São Paulo}

Através da Resolução 4/2000 o Conselho de Educação do Estado de São Paulo (CEESP), embasado na LDBEN (BRASIL, 1996), assume a responsabilidade para regular e avaliar seu sistema de educação superior, propondo nesse ato uma mudança de paradigma na relação Estado-Universidade. Reconhecendo a dimensão sócio-política da avaliação e o impacto e a importância da auto-regulação interna no desenvolvimento das universidades, o CEESP editou uma nova proposta para a avaliação e regulação das Universidades e Centros Universitários estaduais requerendo, de cada uma delas, a elaboração de um projeto de auto-avaliação institucional para um período de cinco anos. (SÃO PAULO, 2000)

Em documento oficial anterior, endereçando a mesma questão, o Conselho já defendia uma sistemática de avaliação diferente para as Universidades ao considerar que:

As instituições de ensino superior, em especial as universidades, como instituições que têm um impacto social muito grande, vêm sendo estimuladas nos últimos anos a avaliar este impacto e também o seu papel. (Que) nesse contexto, a avaliação institucional ganha importância como instrumento não só de autoconhecimento e autodirecionamento, como de prestação de contas ao aluno e à sociedade (...) na medida em que se apresenta como suporte no processo de tomada de decisão para o estabelecimento de novas políticas educacionais intra-institucionais. (SÃO PAULO, 1999, p. 2)

No texto legal, o Conselho Estadual de Educação assume que a avaliação do setor universitário é um elemento essencial no processo de autoreflexão e transformação dos projetos político-pedagógicos da instituição, e que sua função deve ser diagnóstica e formativa. A sistemática de avaliação proposta pelo Conselho reflete essa compreensão e também respeita a autonomia universitária estabelecida pela Constituição Brasileira, adotando um padrão de regulação colaborativa como proposto por Kells (1992). Centrando o processo na avaliação interna da instituição, esta terá a responsabilidade de planejá-lo, de implementá-lo de forma contínua e permanente, de elaborar o relatório do processo de auto-avaliação após três anos, de proceder à avaliação externa por pares, de tomar decisões com base nos resultados e de reportar os resultados do processo ao Conselho Estadual. O relatório final será apreciado por uma Comissão de Especialistas Externos indicada pelo CEESP e pela Câmara de Educação Superior do Conselho Estadual de Educação. 
As idéias básicas que sustentam essa sistemática já estavam presentes na Indicação CEE 6/99 (SÃO PAULO, 1999, p. 4):

A avaliação institucional, calcada nas duas dimensões - a avaliação interna e a externa - ao proporcionar a criação de uma cultura de avaliação, ensejará o cumprimento de três objetivos básicos: o do desenvolvimento de um processo contínuo de aperfeiçoamento do desempenho acadêmico; o de ser um instrumento de planejamento de gestão; e o da prestação de contas à sociedade.

Na exposição de motivos da nova sistemática o CEESP (SÃO PAULO, 2000, p. 3) reconhece ainda que:

A avaliação interna (auto-avaliação) está associada à gestão educacional e a todas aquelas atividades ligadas ao uso efetivo dos produtos da avaliação. Na ausência de um processo de avaliação interna, componente essencial à gestão e à sua lógica, a instituição se desfigura em sua essência. [...] A avaliação interna é um processo permanente de levantamento de informações sobre a realização ou não das metas estabelecidas para a concretização dos objetivos educacionais, científicos, tecnológicos e sociais. [...] É também uma ação solidária, realizada por grupos constituídos e sob a liderança de coordenadores, objetivando o planejamento organizacional e o acompanhamento dos trabalhos a serem desenvolvidos.

Com esse entendimento, o sistema de avaliação proposto pelo CEESP delega a responsabilidade de avaliação para as universidades, respeitando a posição da comunidade acadêmica de "que a universidade pública não é uma mera extensão do Estado ou do governo"; que o processo de autoavaliação institucional é uma condição básica para atendimento da missão da universidade, considerando que "ensino, pesquisa e extensão dependem de liberdade e autonomia política." (MANCEBO, 1998, p. 52)

Em coerência com esses termos, o planejamento e a implementação do processo de avaliação institucional, incluindo a condução da avaliação externa por pares, são delegados às universidades, que reportarão diretamente para o CEESP. Somente após receber o relatório final, incluindo os resultados das avaliações interna e externa, bem como deliberações políticas e administrativas internas para superação das fragilidades detectadas é que o CEESP nomeará uma comissão externa para analisar o relatório, cujo parecer subsidiará a avaliação da Câmara de Educação Superior e do Conselho Pleno do CEESP. A Resolução CEE 004/2000 estabelece, também, que após a análise final o CEESP dará um retorno às Universidades 
dos resultados da avaliação, visando alimentar o próximo ciclo qüinqüenal de avaliação institucional.

O sucesso desse sistema de regulação colaborativo, que ousou mudar, no início desse século, os padrões de regulação prevalentes no país, antes centrado no governo, para um sistema de avaliação colaborativo entre instituições universitárias, pares externos e governo, dependerá, em larga escala, da capacidade das Unidades Universitárias para implementar, em todos os níveis acadêmicos, processos formativos e democráticos de avaliação centrados, portanto, em indicadores de qualidade consensualmente definidos. A implantação desse processo dependerá, em especial, da capacidade de seus líderes, ambos administrativos e acadêmicos, de criarem uma cultura de auto-regulação e um clima de confiança no processo de avaliação, de modo que todas as instâncias acadêmicas possam participar efetivamente da análise e reflexão de seus programas institucionais, articulando esse processo a seus sistemas de gestão, sem que programas e indivíduos sejam penalizados, como preconizado por Kells (1992, p. 61-64).

Estes são os desafios para que a avaliação democrática oportunizada pelo Conselho Estadual de Educação seja efetivamente implementada nas Universidades Estaduais Paulistas. (SÃO PAULO, 2000)

\section{A Universidade Estadual Paulista - UNESP: o contexto institucional}

A Universidade Estadual Paulista (UNESP) é uma universidade pública e multi-campus, com uma estrutura administrativa relativamente descentralizada, com 33 Unidades Universitárias, geograficamente espalhadas em 23 cidades do Estado de São Paulo.

Sua história tem início na década de 20 do século passado, com a política de expansão do sistema de educação superior para o interior do Estado. Com a criação da Universidade Estadual Paulista como uma universidade pública, em 1976, as Faculdades e Institutos Isolados do Estado tornaram-se Unidades Universitárias da UNESP, articuladas pela mesma missão: produzir, preservar e socializar o conhecimento através do ensino, pesquisa e extensão de serviços à comunidade; providenciar ensino público e gratuito de alta qualidade, sem preconceito de qualquer espécie; atribuir graus no campo das artes, das ciências, das humanidades e da tecnologia; formar cidadãos para a investigação e a prática profissional; promover e estimular o debate intelectual e a reflexão permanente sobre a realidade brasileira, em defesa e promoção da cidadania, dos direitos hu- 
manos e da justiça social; promover a extensão de serviços e atividades integrados com a comunidade.

As Unidades Universitárias variam em tamanho e estágio de desenvolvimento, seja em termos de capacidade acadêmica e de pesquisa, seja em termos de suporte administrativo (em particular em relação à disponibilidade de tecnologia de informação e sistema computadorizado).

A UNESP foi criada com uma estrutura acadêmica e financeira centralizada, mas desde 1989, quando as universidades do Estado de São Paulo conquistaram sua autonomia financeira por ato do governo estadual, um programa gradual de descentralização vem se efetivando. Nas Unidades Universitárias, no entanto, há um sistema de descentralização administrativa, com os Chefes de Departamento e representantes da comunidade compartilhando a gestão acadêmica e administrativa.

Atualmente a UNESP é um centro internacional de excelência em ensino e pesquisa. Ela oferece 166 cursos de graduação, 102 programas de mestrado e 88 de doutorado stricto sensu. O corpo docente, composto de 3216 professores concursados (UNESP, 2005) e 503 com contrato temporário (UNESP, 2006), atende pouco mais de 37.000 estudantes. Nacionalmente a UNESP ocupa a quarta posição em produção de pesquisa de acordo com o "academic ranking of world universities" (SHANGAI JIAO TONG UNIVERSITY, 2006) e a sexta posição em número de alunos entre as universidades públicas. (BRASIL, 2003).

\section{O processo de Avaliação Interna da UNESP: Dialogando e construindo consensos}

O processo de Auto-avaliação Institucional na Universidade Estadual Paulista (UNESP) iniciou-se com uma série de conferências e seminários com o objetivo básico de providenciar um fórum de discussão entre a Universidade e o CEESP. Membros do CEESP foram convidados, pela nova reitoria eleita, para discutir com representantes da comunidade e órgãos acadêmicos a nova proposta de avaliação, seus termos de referência, objetivos, mecanismos e processos.

Ao mesmo tempo foram nomeados os membros da Comissão Permanente de Avaliação ${ }^{7}$ (CPA), que assumiu a coordenação dos trabalhos para a elaboração do projeto de avaliação interna.

7 Desde sua fundação, em 1976, a UNESP mantém uma Comissão Permanente para Avaliação dos regimes de trabalho dos docentes em tempo integral (RDIDP) e em turno completo (RTC) na UNESP . Em 1997 essa Comissão foi reestruturada, passando a ser composta por dois grupos de trabalho: o Grupo de Avaliação Docente (GRAD) e o Grupo de Avaliação Institucional (GRAI) que assumiu a coordenação do processo de Avaliação Institucional Interna, vinculado naquela época ao Programa de Avaliação Institucional das Universidades Brasileiras (PAIUB). 
A CPA iniciou os trabalhos pelo resgate, estudo e análise de extensiva documentação da Avaliação Institucional dos Departamentos Acadêmicos, realizada no período de 1992 a 1997, como parte constituinte do PAIUB. Esses estudos e análises providenciaram relevante informação sobre os princípios, objetivos e objetos a serem levados em conta na elaboração do atual projeto, considerando que eles foram definidos com o intenso envolvimento de todas as instâncias e conselhos deliberativos, em especial com a participação dos chefes de departamento, e que esses aspectos haviam sido aprovados pelo Conselho de Ensino, Pesquisa e Extensão (CEPE), órgão máximo de deliberação acadêmica na UNESP.

Por terem sido coletivamente definidos, esses elementos constituíram o ponto de partida para o diálogo e negociação em todas as instãncias de decisões e possibilitaram a construção de uma sólida base teóricoconceitual para o processo de avaliação institucional interna na UNESP.

Outros estudos conduzidos sob a coordenação da CPA, incluindo a análise das reações e questionamentos da comunidade que permearam as iniciativas iniciais para o desenvolvimento do projeto, nos termos estabelecidos pelo CEESP, revelaram a persistência de posições político-ideológicas divergentes sobre os objetivos, as funções e as metodologias a serem utilizadas para avaliar a qualidade acadêmica, e especialmente sobre os usos a serem feitos de seus resultados.

No grupo que sustentava uma posição de resistência à avaliação interna pôde ser identificado um descrédito de que os resultados do processo de avaliação pudessem ser efetivamente utilizados para melhoria da qualidade de programas e projetos institucionais, bem como para subsidiar processos de tomada de decisão nos órgãos colegiados das Unidades Universitárias. Embora houvesse uma expectativa generalizada de que a avaliação deveria servir a esses fins, esse descrédito era alimentado pela prevalência de modelos orientados para o controle no cenário federal, com base em indicadores externamente estabelecidos, elementos esses que fortemente "afetam processos de auto-regulação" (KELLS, 1992, p. 166). Alguns membros da comunidade universitária, no entanto, talvez devido à falta de conhecimento sobre metodologias de avaliação democraticamente orientadas, ou talvez por assumirem um enfoque econômico e de mercado, influenciado pelo cenário de globalização da educação superior como discutido por Dias Sobrinho (2004), defendiam a função de controle e prestação de conta da avaliação institucional e o papel do Estado no estabelecimento de critérios e indicadores comuns, com vistas à comparabilidade do sistema. 
O reconhecimento "dessa epistemologia da complexidade dos significados, de diferenças e contradições" no dizer de Dias Sobrinho (2004, p. 15), alertou para a necessidade de manter ao longo de todo projeto: a) um processo educativo e dialógico sobre as concepções e fundamentos teórico-metodológicos a serem assumidos e que deveriam orientar todo o projeto de avaliação institucional; b) contínua negociação e estudos avaliativos do processo para sustentar o trabalho dos grupos locais de revisão e aperfeiçoamento da avaliação; c) processos de revisão sistemática da condução dos processos avaliativos e de negociação com os líderes acadêmicos e administrativos sobre os termos de referência, visando atingir as consequiências acadêmicas e políticas acordadas no projeto.

Com base nessas primeiras análises e negociações, a primeira ação da CPA foi tornar transparentes os princípios conceituais e procedimentos orientadores acordados, visando auxiliar a CPA na tarefa de delinear e coordenar o processo, bem como aos Grupos de Avaliação Local (GRAL) em suas deliberações no curso de cooperativamente definir as dimensões e elementos da avaliação institucional. Os princípios básicos acordados com a comunidade foram:

- A avaliação institucional na UNESP é proposta como um processo permanente, democrático e participativo para a avaliação de todas as áreas de atividade da vida acadêmica: ensino, pesquisa, extensão de serviços à sociedade e gestão, envolvendo todas as instâncias da Universidade;

- O enfoque de avaliação deve ser consistente com o quadro de referência teórico democraticamente negociado, o que implica em levar em conta os princípios, objetivos e critérios extensivamente discutidos e acordados em todas as instâncias e oficialmente estabelecidos;

- Especial atenção deverá ser dada no estabelecimento de mecanismos para envolvimento de toda comunidade e de todas as Unidades Administrativas na discussão e aprovação das decisões em cada etapa do processo avaliativo e para a criação de uma cultura de comprometimento para o uso apropriado de seus resultados;

- O processo de avaliação será orientado para responder as "grandes questões" relacionadas às dimensões de ensino (de graduação e pósgraduação), de pesquisa, de extensão e de gestão, oficialmente aprovadas pelo Conselho de Ensino, Pesquisa e Extensão (CEPE) como um termo de referência do Projeto de Avaliação Institucional. (UNESP, 2001) 
A primeira versão do projeto elaborada nesses termos de referência e com a contribuição de representantes da comunidade foi disponibilizada para toda comunidade e especialmente encaminhada para discussão e manifestação oficial dos seguintes órgãos e instâncias: CEPE, Pró-Reitorias de Graduação, de Pesquisa, de Extensão e de Administração e Unidades Universitárias. Cada uma das 25 Unidades Universitárias discutiu o AnteProjeto de Avaliação Institucional e as considerações e sugestões aprovadas pelas Congregações foram encaminhadas de volta à CPA.

A CPA assumiu a responsabilidade de analisar as contribuições das Unidades, revisar o projeto e encaminhar um relatório pessoal a cada uma das Unidades, dando conta das considerações e sugestões por elas apresentadas. A versão final do Projeto de Avaliação Institucional foi apreciada pelo CEPE e, após aprovada, encaminhada ao CEESP.

Para garantir o princípio democrático de igualdade de participação o CEPE e a CPA realizaram uma reunião conjunta com todos os diretores das Unidades Universitárias para viabilizar a criação dos Grupos Locais de Avaliação (GRALs), com as principais funções de coordenar e acompanhar o processo de avaliação em todas as atividades da vida acadêmica; promover e estimular processos de sensibilização para envolvimento da comunidade local; articular as contribuições dos participantes locais; manter o relacionamento entre a Unidade e a CPA; e coordenar a elaboração de relatórios parciais e final.

Com o objetivo de garantir também que o processo fosse responsivo para a variedade de valores, interesses e necessidades dos diferentes grupos foi dado poder aos grupos locais para participarem da definição das informações a serem coletadas, do estabelecimento de critérios para julgamentos de valor sobre as "grandes questões" a serem respondidas nas dimensões da vida acadêmica e para elaborarem instrumentos e técnicas de avaliação, quando considerados apropriados.

\section{O Projeto de Auto-Avaliação Institucional da UNESP}

\section{A Concepção e as Funções da Avaliação}

A avaliação institucional na UNESP é pensada como um compromisso com "a construção de uma consciência institucional, tendo em vista possibilitar que os resultados obtidos forneçam os subsídios necessários à reflexão e revisão de políticas, programas e projetos que favoreçam os processos de auto-gestão em todas as instâncias da universidade". (UNESP, 2001, p. 8) 
O Projeto de Avaliação Institucional (UNESP, 2001, p. 10), tomando como referência trabalho desenvolvido por Grego (1999) sobre o modelo de avaliação em construção na UNESP desde 1991, explicita essa concepção ao definir as funções da avaliação:

Buscando tornar significativo o processo de Auto-Avaliação Institucional na UNESP, parte-se de grandes questões relativas a cada uma das dimensões a avaliar e atribui-se-lhe três grandes funções: diagnóstica, formativo-reflexiva e crítica e transformadora.

O autoconhecimento institucional é buscado, em um primeiro momento, através da função diagnóstica da avaliação.

A função diagnóstica visa o autoconhecimento da instituição. Mediada pela CPA, envolve o processo de definição de indicadores e variáveis pela comunidade e a obtenção, análise e tratamento dos dados em diferentes instâncias da Universidade. Em cada instância a avaliação se orienta para o conhecimento sistemático do trabalho acadêmico desenvolvido, seu progresso, limitações e deficiências no atendimento aos programas e projetos acadêmico-institucionais. (UNESP, 2001, p. 10-11)

O exercício da função formativo-reflexiva, que envolve julgamento de valor, ocorre quando os participantes questionam os dados resultantes tanto da avaliação interna como externa e refletem sobre seus projetos e programas de ensino, pesquisa e extensão, bem como sobre seus processos e políticas de gestão. A função crítica e transformadora só se expressa efetivamente quando as Unidades Universitárias, após analisarem os resultados da avaliação interna à luz dos relatórios dos avaliadores externos, elaboram seus relatórios finais e tomam decisões a respeito das recomendações apresentadas. É a articulação das funções diagnóstica, formativa e crítica que torna possível o exercício pleno do processo de auto-gestão em todos os níveis e instâncias da universidade.

O termo "auto-gestão" é utilizado no sentido do termo "autoregulação", como definido por Kells (1992, p. 16). Nesse sentido, autogestão envolve autoconhecimento da qualidade dos projetos e programas institucionais em termos de sua contribuição para a sociedade (sua relevância para a educação contínua de recursos humanos, a produção e socialização do conhecimento, a melhoria da qualidade de vida da sociedade e o exercício de sua função crítica na sociedade), através de avaliação interna e externa por pares; da identificação de seus pontos fracos e fortes; do poder compartilhado para tomar decisões sobre o que necessita ser modificado ou renovado. 
A avaliação para a auto-gestão na UNESP é proposta em articulação com a nova política de descentralização administrativa e com o novo requerimento para que cada Unidade Universitária elabore, periodicamente, seu próprio Projeto de Desenvolvimento Institucional.

A avaliação Institucional foi também pensada como um poderoso mecanismo de prestação de contas à sociedade. Começando com grandes questões, a avaliação institucional visa dar contas da contribuição da Universidade para a sociedade. Como exemplos dessa orientação podem-se destacar algumas das "Grandes questões" da dimensão ensino de graduação, constantes do Projeto de Avaliação Institucional da UNESP (2001, p.13-14).

Qual o impacto e eficácia da atual política de acesso na UNESP no atendimento à sua responsabilidade como universidade pública de garantir educação superior de qualidade, alicerçada na excelência científica e acadêmica, mas com equiidade e relevância social de forma a estabelecer uma política de inclusão que possibilite o acesso a amplos segmentos da sociedade, inclusive aos oriundos de classes menos favorecidas? Quais as taxas de evasão e de progressão dos alunos ao longo do curso? Que fatores estruturais e organizacionais têm favorecido e/ou interferido na evasão e progressão ao longo do curso? Qual a importância/impacto dos programas de bolsas de estudo na formação acadêmica dos alunos?

Nesses termos, mas elaborado por iniciativa do Governo do Estado, o processo de Avaliação Institucional na UNESP visou o atendimento de duas funções básicas: prestar contas do impacto e relevância do trabalho da universidade para a sociedade e "oferecer à comunidade interna subsídios no processo de reflexão e transformação de seu próprio projeto acadêmico-institucional". (UNESP, 2004, p. 3)

\section{O Referencial Teórico-Metodológico da Avaliação}

Tendo como referência a missão e as características da UNESP, os princípios da Avaliação Institucional, amplamente discutidos e aprovados pelas congregações de todas as Unidades Universitárias foram: Totalidade, Igualdade, Legitimidade Política e Técnica, Cumulatividade, Reciprocidade, Comparabilidade, Articulação, Dialogicidade e Racionalidade.

Embasados nesses princípios e nos objetivos e funções coletivamente assumidos na UNESP (UNESP, 1997), foi elaborada uma proposta de Avaliação Institucional orientada por três enfoques teóricos: o modelo de ava- 
liação para a tomada de decisão, de orientação quali-quantitativa proposto por Stufflebeam e Webster (1991) e Stufflebeam (1997, 2004); o enfoque de avaliação democrática conforme proposição de MacDonald (1974) e Elliot (1991); e a perspectiva de avaliação institucional crítica e transformadora de Kemmis (1989).

Esses enfoques proporcionaram as orientações metodológicas visando atender os requerimentos de um processo dialógico, significando que a avaliação institucional é uma tarefa a ser realizada com a participação de todos os membros envolvidos e/ou afetados pelo processo; que a responsabilidade para auto-avaliação, incluindo o julgamento de todos os projetos intelectuais e pedagógicos, é competência de cada grupo e instância deliberativa dentro da Universidade; que os resultados devem servir para o autoconhecimento da universidade sobre suas práticas e projetos e para iluminar as audiências e os gestores no processo de repensá-los; e para estimular um ambiente cooperativo de debate e negociação "em todas as instâncias da Universidade de forma a subsidiar a auto-gestão, o aperfeiçoamento e a articulação contínuos dos programas e projetos acadêmicos, na busca da melhoria da qualidade do ensino, da pesquisa, da extensão e da gestão universitária." (UNESP, 2001, p. 9)

\section{Os Esforços de Construção de um Processo Democrático e Unificado de Avaliação Interna}

\section{A Sensibilização das Unidades Universitárias}

A CPA visitou todas as 25 Unidades Universitárias e discutiu o Projeto de Avaliação com as comunidades locais em Seção Aberta da Congregação, visando atingir cinco objetivos centrais: sensibilizar docentes, funcionários e alunos para participarem do processo; apresentar as etapas do projeto de avaliação e discutir seus termos de referência, dialogando com a comunidade sobre a participação dos atores nas sucessivas ações ao longo do ciclo de cinco anos; discutir as "grandes questões" a serem respondidas em cada uma das dimensões a serem avaliadas (ensino de graduação e de pós-graduação, pesquisa, extensão e gestão), definindo quem deveria coordenar o processo de avaliação em cada uma das dimensões; estimular a comunidade local a participar do processo de definição sobre "o que" avaliar e sobre "critérios e indicadores a serem priorizados dentro de cada dimensão"; e conferenciar com os Grupos de Avaliação Local (GRAL). Nas Unidades em que o GRAL ainda não estava constituído o trabalho da CPA foi de estímulo e orientação à sua implantação. 
Seguindo arranjos coordenados pela CPA, cada encontro começou com uma explanação do Diretor da Unidade sobre a missão, programas, recursos, produção e iniciativas acadêmicas específicas.

Durante esses encontros membros da CPA atuaram como observadores, fazendo registros e gravando as falas dos participantes. Essa foi a primeira ação de um estudo de meta-avaliação formativa conduzida pela CPA para monitorar o processo de avaliação, perceber identidades e conflitos de valores e interesses entre grupos participantes, identificar problemas e restrições que poderiam interferir na definição e implementação de um processo democrático orientado para a auto-gestão, nos termos estabelecidos no Projeto de Avaliação Institucional, bem como para identificar necessidades locais por informações e orientação de especialistas e de recursos.

A análise desses registros gerou um quadro realista da situação e das condições de cada Unidade para conduzir seu próprio processo de avaliação local, indicando a necessidade de colaboração de especialistas externos em avaliação e de criação de uma Comissão de Especialistas e de um Ambiente de Aprendizagem e de Suporte Técnico-científico para assistir os GRALs no desenvolvimento e implementação de seus processos internos.

\section{Criando um Núcleo de Estudos e de Recursos em Avaliação Institucional}

Tendo como objetivos fornecer orientação e assessoramento tanto de natureza teórico-metodológica como técnica no desenvolvimento e implementação dos processos de avaliação; criar um banco de dados; e providenciar assistência na análise estatística dos dados aos Grupos de Avaliação Locais, uma Comissão de Especialistas foi constituída envolvendo especialistas nas áreas de avaliação, estatística e computação, a qual, ao longo de todo o processo, atuou em cooperação com o GRAI, compondo com este uma Comissão Ampliada de Avaliação.

Considerando a ausência de um banco de dados na UNESP, que pudesse receber os dados a serem coletados de todas as Unidades e suportar as demandas do processo de avaliação em curso, o Grupo Coorporativo de Sistemas (grupo da reitoria voltado para o desenvolvimento de Sistemas Coorporativos Informatizados) passou a oferecer suporte técnico ao processo de avaliação e dois especialistas desse grupo foram incorporados à Comissão Ampliada de Avaliação. 
Essa Comissão Ampliada de Avaliação, em seus esforços para atender às demandas de orientação e suporte especializado dos GRALs, organizou um Núcleo de Estudos e Recursos em Avaliação Institucional, desenvolvendo uma série de ações e produtos entre os quais pode-se destacar a realização de conferências e oficinas, a produção de materiais de referência e de apoio conceitual e técnico, um centro de atendimento por telefone e on-line e a criação de um link de avaliação institucional no site da universidade.

\section{Aprendendo com Especialistas e Experiências Bem- Sucedidas: Um processo de reflexão em ação}

Compromissada com o aperfeiçoamento do processo de avaliação e com o aperfeiçoamento dos GRALs, a Comissão Ampliada de Avaliação empreendeu uma série de estudos sobre experiências bem sucedidas de avaliação institucional no Brasil e no exterior, através de consultas a materiais de referência e visitas in loco a instituições brasileiras, para explorar políticas e mecanismos técnicos alternativos, bem como esquemas para a implementação democrática das diferentes fases do processo de avaliação. Dentre as experiências estudadas, a que teve maior influência na condução dos trabalhos na UNESP foi a da Universidade Federal do Rio Grande do Sul (LEITE, TUTIKIAN, HOLZ, 2000), que providenciou tanto mecanismos úteis para sustentar o trabalho de avaliação nas Unidades com estágios de desenvolvimento, necessidades, demandas e expectativas diferentes (uma realidade continuamente presente em nossa universidade multicampus) como os critérios e quadros conceituais de referência para a organização da avaliação externa.

Ao longo de todo o processo, com base nesses estudos e nos estudos diagnósticos e de acompanhamento do processo junto às Unidades, a Comissão Ampliada de Avaliação atuou como um grupo de reflexão da e na ação analisando dados e discutindo caminhos alternativos para superar os problemas. Em diferentes momentos o grupo foi ampliado para envolver os membros dos Grupos de Avaliação Local.

Com o mesmo propósito, especialistas do Brasil, dos Estados Unidos e da Escócia foram convidados para compartilhar suas experiências com o grupo através de seminários, conferências, e oficinas em diferentes fases do processo.

O resultado mais significativo dessas sessões de estudo compartilhadas foi a capacitação dos participantes (em especial dos membros dos GRALs que se envolveram ativamente no processo) para conduzirem pro- 
cessos democráticos de avaliação, orientados para a auto-gestão das atividades acadêmicas.

A primeira oficina (Oficina I) foi projetada com três objetivos: fazer um diagnóstico dos avanços e dificuldades dos Grupos de Avaliação Locais na implementação do Projeto de Avaliação Institucional em suas Unidades; constituir-se em fórum de discussão e articulação dos Grupos de Avaliação das 25 Unidades Universitárias; e estabelecer termos de referência e procedimentos para o trabalho de definição dos objetos, critérios e processos de avaliação nas dimensões de ensino, pesquisa, extensão e gestão nas Unidades Universitárias.

Iniciando a Oficina I os representantes de cada Unidade, com base em questões encaminhadas previamente e discutidas localmente, foram convidados a reportarem o processo em desenvolvimento, as restrições e problemas encontrados e as estratégias utilizadas para sua superação. $\mathrm{Na}$ segunda fase da Oficina, os membros dos GRALs, reunidos em grupos, realizaram um exercício conjunto de definição dos objetos e indicadores na dimensão ensino de graduação, selecionada pela comunidade para ser o foco da avaliação institucional na UNESP.

Os participantes da Oficina I apontaram uma série de problemas e restrições, alguns deles já identificados em estudos anteriores conduzidos pela CPA, entre os quais se destacaram: a falta de uma cultura de avaliação nas comunidades locais; a ausência de conhecimentos especializados e de experiência no desenvolvimento de mecanismos, procedimentos e instrumentos de avaliação, divergências conceituais entre os participantes, considerando que professores e pesquisadores pertencem a grupos intelectuais específicos, com seus próprios valores e formas de enfocar a realidade, os quais orientam para diferentes concepções e metodologias de avaliação; a ausência de apoio político e de suporte estrutural e financeiro em algumas unidades; e diferenças importantes em recursos computacionais entre as Unidades Universitárias.

Diagnosticadas essas restrições, os participantes da oficina acordaram que a Comissão Conjunta CPA/CE organizaria seminários regionais de orientação e suporte para a definição de objetos e indicadores para avaliação de todas as dimensões da vida acadêmica; que as Unidades encaminhariam suas sugestões e propostas à CPA e que a Comissão Conjunta CPA/CE trabalharia as propostas das Unidades, articulando-as e organizando-as dentro de cada dimensão de modo a criar um quadro de referência comum, que seria encaminhado para cada Unidade para discussão e aprovação. Essa estratégia possibilitou a elaboração de um quadro de refe- 
rência sólido e unificado para a Avaliação Institucional na UNESP, em coerência com os princípios que política e teoricamente a norteiam.

Para a consolidação das propostas no âmbito das Unidades Universitárias foram realizadas duas Oficinas que se repetiram em quatro diferentes regiões do Estado e um seminário, realizado em São Paulo, com a participação da Dr ${ }^{\mathrm{a}}$ Pamela Moriearty da University of Illinois (USA). Além disso, para suprir a falta de conhecimentos especializados e de recursos administrativos nas Unidades, arranjos foram feitos para manter um serviço de assessoria e acompanhamento por telefone e através da intranet, bem como para produção de materiais de referência. Ao mesmo tempo o presidente da CPA envolveu-se em intensa negociação e acordos com autoridades e setores administrativos da reitoria visando atendimento a demandas por suporte político, técnico e estrutural dos Grupos de Avaliação Locais.

\section{Definindo Objetos, Indicadores e Descritores Qualitativos: uma construção coletiva}

Tendo como ponto de partida a proposta de avaliação anteriormente consensuada pela comunidade acadêmica e os termos de referência do Conselho de Educação do Estado de São Paulo, a UNESP definiu como foco central da avaliação "a produção da universidade em suas funções básicas de ensino, pesquisa e extensão e as condições infra-estruturais que condicionam a realização dessas funções: o processo de formação de recursos humanos e as atividades acadêmico-administrativas." (UNESP, 2001, p. 11)

Considerando, no entanto, a multidimensionalidade e pluralidade dessas funções, as quais se desdobram na prática cotidiana em diversificados objetos específicos, e que a responsabilidade para definir os objetos da avaliação deve ser compartilhada por todos os membros da comunidade, esforços foram feitos para envolver ativamente a comunidade no âmbito das Unidades Universitárias. Nesse sentido, os Grupos de Avaliação Locais, ao mesmo tempo em que participavam de estudos e discussões com a Comissão Conjunta CPA/CE, responsabilizavam-se, em suas Unidades, pelo processo de envolvimento dos Conselhos de Curso de Graduação e Pós-graduação, das Comissões Permanentes de Extensão e das Comissões de Pesquisa nas discussões para definição dos objetos, indicadores e descritores qualitativos da avaliação institucional, os quais uma vez definidos e aprovados pela Congregação foram encaminhados à CPA.

As propostas e sugestões vindas das Unidades enfatizavam a necessária complementaridade da avaliação qualitativa e quantitativa. $\mathrm{Na}$ dimensão ensino de graduação os descritores qualitativos foram considera- 
dos essenciais para providenciarem uma descrição compreensiva da relevância social, científica e cultural e do impacto dos cursos de graduação, bem como para identificar percepções e julgamentos divergentes dos diferentes grupos de interesse (estudantes, professores e funcionários administrativos). Para atendimento desses objetivos os esforços se orientaram no sentido de produzir indicadores quali-quantitativos, entendidos como um conjunto de itens de informação, os quais selecionados e agregados de acordo com uma racionalidade implícita possibilitassem avaliar a qualidade, a relevância e/ou o impacto dos projetos e programas institucionais. Um exemplo de um indicador quali-quantitativo é a "trajetória educacional pregressa" dos ingressantes nos cursos de graduação, considerada um indicador da eficácia da política do vestibular em garantir a eqüidade de acesso na UNESP. Esse indicador agrega informações sobre a relação de ingressantes "oriundos de escola pública versus escola privada", "oriundos de cursos noturnos versus diurno" e que "freqüentaram cursinhos preparatórios ou não".

Embora todas as Unidades Universitárias tenham participado, encaminhando uma relação de objetos e indicadores que consideravam relevantes para serem avaliados em cada dimensão da vida acadêmica, diferenças na qualidade de contribuição de cada uma delas, quando analisadas à luz de extensa documentação coletada pela Comissão Conjunta CPA/CE em seus estudos de meta-avaliação, podem ser atribuídas seja ao grau de envolvimento dos setores representativos da Unidade, seja ao suporte político e estrutural providenciado pelas administrações locais.

A partir das propostas das Unidades, os objetos, variáveis, indicadores e descritores qualitativos foram estruturados pela Comissão Conjunta em uma matriz, dentro de cada dimensão, e conjuntos deles relacionados às grandes questões a serem respondidas no primeiro ciclo de avaliação de cinco anos. Essa matriz foi enviada às Unidades para novas discussões na comunidade, apreciação e aprovação pelas Congregações e retorno à CPA/ CE com sugestões e contribuições.

A CPA assessorou o GRAL das Unidades no trabalho com a matriz oferecendo orientação teórica e técnica através de: a) texto elaborado para explicitar os fundamentos conceituais e termos de referência da matriz; b) seminários regionais para discussão sobre a composição dos indicadores quali-quantitativos; c) orientação e suporte técnico para a coleta e análise dos dados de forma agregada e articulada, em cada Unidade Universitária.

Esse processo estimulou intensa participação dos membros do GRAL na maioria das Unidades, e foi considerado por eles relevante para "aumentar a confiança” dos participantes na avaliação e para "legitimar o 
processo", ajudando a construir "uma linguagem comum" para pensar a avaliação institucional.

A matriz das dimensões a serem avaliadas foi bem recebida pela maioria dos Grupos de Avaliação Locais, que reconheceram que seu conteúdo "representa as idéias de toda comunidade e respeita as especificidades do trabalho acadêmico realizado nas Unidades." 8

\section{Construindo Instrumentos, Coletando, Analisando e Discutindo os Dados}

Em atendimento à solicitação das Unidades e com base na matriz a Comissão Conjunta CPA/CE elaborou a metodologia e os instrumentos para avaliação quantitativa dos dados nas dimensões ensino de graduação e pós-graduação, pesquisa, extensão e gestão com base na matriz e disponibilizou-os on-line, via intranet. Instrumentos para avaliação dos exalunos de graduação e de Pós-graduação foram também elaborados pela Comissão e disponibilizados on-line. As Unidades, sob coordenação dos Grupos de Avaliação Locais, providenciaram dados descritivos e elaboraram instrumentos e técnicas de avaliação das percepções e julgamentos dos diferentes segmentos da comunidade (alunos, professores e funcionários) sobre aspectos do trabalho e da vida acadêmica nas dimensões consideradas, e também coletaram os dados e preencheram os questionários online. Ao longo de todo esse processo a Comissão Conjunta providenciou treinamento específico para os representantes indicados pelas Unidades e os assistiu na coleta de informações e no preenchimento dos dados dos questionários, os quais foram armazenados no Banco de Dados da Reitoria, estruturado especialmente para assistir o processo de avaliação institucional. O Grupo Operativo de Sistemas da Reitoria processou os dados e encaminhou relatórios a cada Unidade para análise e interpretação.

\section{Elaboração, Análise e Discussão do Primeiro Relatório}

Embora o nível de envolvimento e participação das comunidades locais no processo de discussão dos resultados e na elaboração do Relatório Parcial da Avaliação tenha variado muito de Unidade para Unidade, todas elas trabalharam intensamente na elaboração do relatório, tentando atender todos os termos de referência coletivamente estabelecidos. Além disso, todas as Congregações locais apreciaram e aprovaram o relatório elaborado sob coordenação do GRAL e o encaminharam à CPA.

8 Falas de membros dos Grupos de Avaliação Locais registradas durante participação nos Seminários Regionais e expressas em relatórios de apreciação da Matriz encaminhados pelas Unidades à CPA 
Após exaustiva análise dos relatórios das Unidades pela Comissão de Especialistas, com base em critérios estabelecidos, a Comissão Conjunta CPA/CE assumiu a responsabilidade de reportar os resultados da análise às Unidades e de realizar visitas técnicas de assessoramento visando aperfeiçoamento dos relatórios antes de serem encaminhados ao CEPE e ao Conselho Estadual de Educação para análise e apreciação.

Ao mesmo tempo os dados de toda a UNESP foram processados pelo Grupo de Sistemas Operacionais e disponibilizados para a Comissão Conjunta CPA/CE que sistematizou, analisou os dados e elaborou o Relatório Geral da UNESP.

Concluídos os relatórios realizou-se o I Seminário de Avaliação Diagnóstica da UNESP. Sob a coordenação da Comissão Conjunta CPA/ CE e com a participação dos Grupos de Avaliação Locais, dos Diretores das Unidades Universitárias, dos Pró-Reitores de Graduação, Pesquisa e Pós-Graduação, Extensão e Gestão, do CEPE e representantes da Reitoria o processo e os resultados da Avaliação Institucional da UNESP foram analisados e discutidos, decisões foram tomadas para a continuidade do processo de avaliação e, em especial, delineou-se o processo de avaliação externa, deliberando-se que o foco seriam os 166 cursos de graduação da UNESP.

O seminário constituiu-se em fórum privilegiado para a discussão dos termos de referência e dos critérios para a avaliação externa. As propostas elaboradas durante o seminário foram rediscutidas nas Unidades Universitárias e sistematizadas pela Comissão conjunta CPA/CE. Como constou das "diretrizes para a avaliação externa" ficou definido que os avaliadores externos trabalhariam com os seguintes termos de referência: descrição da Missão da instituição e do curso no contexto da Universidade e da Sociedade; Relatório Parcial da Avaliação Institucional da Unidade/ Curso; visitas a instalações e serviços; entrevistas com docentes, funcionários e alunos; entrevista com o Conselho do Curso. Ficou decidido também que os avaliadores externos seriam solicitados a emitir parecer sobre: a qualidade de ensino do curso, tendo como parâmetro a sua evolução histórica e suas condições estruturais; os pontos fortes do curso, que deveriam ser mantidos; os pontos críticos do curso, que deveriam ser melhorados; recomendações e sugestões a curto e médio prazo.

\section{Refletindo sobre o Processo: Um Estudo de Meta-avaliação}

A reflexão sobre o processo de avaliação interna, com base em registros de observação, depoimentos e estudos de meta-avaliação, possibilitou à Comissão Conjunta CPA/CE identificar um conjunto de fatores que 
contribuíram significativamente seja para a condução de um processo cooperativo de planejamento e implementação da avaliação, seja para a construção de um quadro de referência conceitual. Esse processo possibilitou articular e agregar os dados coletados em resposta às grandes questões relacionadas à missão da universidade nas dimensões de ensino, pesquisa, extensão e gestão. Dentre os fatores que contribuíram significativamente para o processo cooperativo destacam-se: a) o elevado compromisso dos membros dos Grupos de Avaliação Local com a melhoria da qualidade da vida e do trabalho acadêmico e da organização institucional na UNESP; b) a criação e manutenção de um núcleo de estudo e de assessoramento e suporte técnico-científico junto à $\mathrm{CPA}$; c) os esforços empreendidos para garantir um ambiente interativo e dialógico entre os grupos de avaliação da reitoria e das Unidades Universitárias, e para estimular os grupos locais a assumirem o poder de conduzirem e responderem por seus próprios processos de avaliação e pelo uso de seus resultados; d) o apoio político e administrativo do Reitor e do CEPE e o apoio financeiro e estratégico da VUNESP (Fundação para o Vestibular da UNESP); e) a composição multidisciplinar da CPA/CE que possibilitou o oferecimento de orientação e assessoramento técnico-científico constante em diferentes áreas do conhecimento e sua atuação como um grupo reflexivo ao longo de todo processo, coletando dados, analisando-os, refletindo sobre o processo em conjunto com representantes da comunidade e propondo correção de rumos e procedimentos, visando tornar a avaliação mais responsiva às demandas da comunidade e à multidimensionalidade institucional.

Há clareza de que nenhum desses fatores respondeu sozinho pelo sucesso do empreendimento. O certo é que o conjunto desses fatores providenciou uma base política, estrutural e técnico-científica para a construção de uma avaliação institucional democrática, orientada para a auto-gestão e responsiva às grandes questões assumidas pela comunidade interna, bem como aos parâmetros definidos pelo Conselho Estadual de Educação do Estado de São Paulo.

\section{O Compromisso com a Melhoria da Qualidade Acadêmico- Institucional}

Tendo como foco da avaliação as atividades essenciais relacionadas à missão da universidade, e respeitando que a avaliação deve "favorecer o debate crítico sobre a qualidade do trabalho acadêmico" em todos os níveis e instâncias, assumiu-se que cada membro da comunidade que tivesse um compromisso genuíno em relação a quaisquer dimensões da vida aca- 
dêmica deveria participar ativamente das decisões sobre o processo de avaliação.

Considerando, ainda, que o sistema universitário funciona na base de conselhos ou comissões representativas, foi consensualmente estabelecido que os Conselhos e Comissões deliberativas, relacionados com as dimensões a serem avaliadas (Conselhos de Curso de Graduação e de Pósgraduação, Comissões de Extensão e de Pesquisa) seriam chamados a colaborar com o GRAL local na coordenação do processo de avaliação da dimensão pela qual respondem na Unidade.

Na maioria das Unidades, todos os Conselhos atuaram em colaboração com o GRAL, assumindo a coordenação da respectiva dimensão e promovendo discussões com a comunidade para a definição dos objetos, indicadores e critérios de avaliação, e desenvolvendo instrumentos para avaliação do ambiente institucional e de ensino e aprendizagem junto aos alunos, professores e funcionários. Como órgãos legítimos de coordenação e monitoramento de programas e projetos nas dimensões de ensino, pesquisa, extensão e gestão eles se encontram em uma posição privilegiada para focar a avaliação nas questões de interesse essencial para o contexto em que se inserem e, dessa forma, obter informações relevantes para subsidiar processos de decisão interna.

As observações in loco e a extensa documentação permitiram confirmar que a efetividade e intensidade do envolvimento desses conselhos no processo de avaliação constitui-se em um dos fatores mais relevantes na construção de processos democráticos e na apropriação dos resultados para informar decisões acadêmicas e administrativas no âmbito das Unidades. Dados coletados junto às Unidades Universitárias evidenciam que as Unidades que atingiram altos níveis de envolvimento de seus órgãos colegiados lograram criar uma cultura de avaliação democrática e orientada para a auto-gestão. Os membros dos Grupos de Avaliação dessas Unidades foram também os que participaram mais ativamente dos Seminários e Oficinas organizados pela CPA/CE e que mais contribuíram nas discussões coletivas.

Esses dados permitiram evidenciar, ainda, que as demandas nessas Unidades eram altas e que a legitimidade do processo estava intimamente ligada não só à representatividade dos grupos coordenadores, mas à capacidade desses grupos em sustentarem e socializarem um quadro de referência conceitual, em articularem informações e indicadores para responder às questões centrais da avaliação institucional. A legitimidade desses órgãos possibilitou ainda referenciar os resultados da avaliação aos programas e projetos em desenvolvimento na Unidade. Em algumas dessas 
Unidades os resultados da avaliação externa dos cursos de graduação ensejou, concretamente, discussões na comunidade e orientou o processo de tomada de decisão dos órgãos colegiados visando melhoria da qualidade do ensino.

\section{O Núcleo de Estudos como elemento formativo do Processo de Avaliação}

A natureza democrática do processo de avaliação interna na UNESP, baseado nos princípios de autonomia e liberdade acadêmica, significa que a avaliação institucional é tarefa a ser efetivada no coletivo, que a qualidade do trabalho acadêmico não é determinada por um único indivíduo ou grupo, nem suporta o privilégio de uma função em detrimento de outras. Assim, entendeu-se que a função formativa da Universidade somente poderia ser atingida pela ação conjunta dos grupos acadêmicos e comissões deliberativas em suas atividades de ensinar, de pesquisar, de trabalhar com a comunidade e de refletir sobre a melhor maneira de alocar recursos para o cumprimento de sua missão educativa, quando subsidiada por um processo de avaliação também formativo.

Dada a ausência de uma cultura de avaliação formativa, e a tradição dominante de avaliação somativa, centrada em resultados e orientada para o controle, o processo de avaliação institucional na UNESP foi assumido como formativo em dois sentidos: a) como um processo de construção da qualidade institucional e; b) como um processo de construção da qualidade da avaliação, incluindo o processo de qualificação dos avaliadores.

Esse caráter formativo foi buscado na criação de um núcleo de estudos e de aprendizagem, que possibilitasse um ambiente coletivo de reflexão e de diálogo ao longo de todo o processo de avaliação e a emergência de idéias e estratégias que tornasse a avaliação útil e significativa para toda a comunidade. Esse ambiente foi sendo construído nas visitas às Unidades, nas Oficinas, nos Seminários e Conferências com especialistas, em grupos de estudos de materiais de referência, através de textos produzidos pelos especialistas internos, de guias de trabalho e de instrução, de memorandos, dos serviços de intranet e de e-mails; e de um serviço telefônico disponibilizado para os Grupos de Avaliação Locais.

Os momentos de partilha e troca de idéias, altamente demandados pelos membros dos GRALs, foram considerados a melhor estratégia para enriquecer cada participante em sua capacidade para conduzir e para lidar com os processos internos de avaliação em desenvolvimento nas Unidades Universitárias. As experiências mais enriquecedoras foram as Oficinas, 
tanto as realizadas internamente com os membros dos GRALs, como as compartilhadas com especialistas externos à UNESP. Esse espaço de aprendizagem compartilhada estimulou o diálogo constante entre as diversas comunidades internas da UNESP e destas com os especialistas externos, viabilizando a emergência de uma linguagem e de um referencial comum para o exercício da avaliação institucional, um dos problemas centrais enfrentados na UNESP, dada sua característica multi-campus.

$\mathrm{Na}$ fase de coleta e de análise, tratamento e discussão dos dados, o treinamento para operação do sistema on-line providenciado pelo Grupo de Sistemas Cooperativos garantiu a correta obtenção e digitalização dos dados, possibilitando a elaboração de relatórios técnicos a todas as Unidades. A assessoria dos membros da Comissão Conjunta CPA/CE e os materiais de referência elaborados pelos especialistas em avaliação ajudaram a construir uma identidade de pensamento e de procedimentos, fundamental para orientar as ações avaliativas nas Unidades, em especial na construção da matriz de objetos, indicadores e descritores qualitativos, na análise, interpretação e discussão dos dados e na elaboração dos relatórios pelos grupos locais.

No entanto, estimular a interação dos diferentes grupos participantes, em especial mantê-los engajados em um diálogo construtivo, não foi tarefa fácil. Foi necessário alargar nossa compreensão sobre a diversidade de contextos e estar constantemente abertos para uma multiplicidade de perspectivas sobre avaliação e sobre questões acadêmicas de modo a identificar e, quando possível, buscar a conciliação e/ou superação de posições divergentes, as quais muitas vezes perturbaram o processo ou puseram em risco princípios éticos assumidos na condução da avaliação.

\section{O Apoio Político e Administrativo na UNESP}

O caráter institucional da avaliação na UNESP se expressa nos princípios de universidade/totalidade e de legitimidade política, definidos historicamente pela comunidade, e claramente assumidos no projeto de avaliação da UNESP. (UNESP, 2001)

O princípio de universidade/totalidade significa que a avaliação deve respeitar as relações sociais e de trabalho estabelecidas no processo organizacional, que enfatizam o exercício da democracia em todos os níveis e instâncias de decisão da estrutura universitária. Assumir esse princípio implicou que nenhuma interferência autoritária deveria ser feita nas Unidades e requereu estratégias efetivas para o envolvimento da direção. Esse envolvimento foi obtido graças ao empenho e apoio político da Reitoria e, 
em especial, do CEPE ao processo de avaliação. Esse apoio se fez presente de muitas formas: no agendamento de reuniões com os diretores das Unidades, com os membros dos GRALs e com membros do Conselho Estadual de Educação; na mediação do diálogo com diferentes grupos de interesse, assumindo e defendendo pública e politicamente os princípios e termos de referência do projeto de avaliação; e colaborando na divulgação do Projeto e dos Relatórios junto à comunidade. O Reitor e o CEPE, e em especial seu presidente, na qualidade de Vice-Reitor da Universidade, atuaram em defesa de suporte financeiro para sustentar o processo de avaliação.

No âmbito das Unidades Universitárias, o compromisso político da Diretoria, da Congregação e do Grupo de Avaliação Local, bem como das Comissões locais deliberativas em ensino, pesquisa, extensão e gestão, caracterizou-se como fator determinante para o sucesso da avaliação institucional, em especial para o desenvolvimento de um processo democrático de discussão dos resultados e de seu uso para informar as decisões acadêmicas e administrativas. $\mathrm{O}$ apoio político, traduzido em suporte organizacional e estrutural, fez uma diferença substancial na promoção de ações para o envolvimento da comunidade, no desempenho dos grupos de avaliação local para o planejamento de processos internos de auto-avaliação, no oferecimento de suporte de informática para obtenção e tratamento dos dados, que se refletiram na qualidade dos relatórios apresentados. Em contraste, a ausência de apoio político da administração local afetou negativamente o trabalho dos Grupos de Avaliação Local, inviabilizando ações de sensibilização da comunidade e, em conseqüência sua participação no processo. A ausência de recursos dificultou, ainda, o trabalho do GRAL em relação ao desenvolvimento de instrumentos e técnicas de avaliação para obtenção de dados qualitativos e, conseqüentemente, comprometeu o uso dos resultados de avaliação para tomar decisões sobre os projetos e programas acadêmicos.

\section{O papel da Comissão Conjunta CPA/CE como grupo de sustentação do processo de ação e reflexão}

O exercício do princípio da dialogicidade implicou o reconhecimento de que "uma das funções da avaliação é favorecer o debate crítico sobre a qualidade do trabalho acadêmico entre os diferentes grupos e áreas de conhecimento da Universidade, nas suas diversas instâncias" (UNESP, 2001, p. 8). Exigiu também o reconhecimento de que embora esse debate já exista no interior da universidade, ele é multidimensional e plural, envolvendo múltiplos elementos e perspectivas. Na prática, esse reconhecimento sig- 
nificou que a avaliação passou a abarcar uma variedade de objetos e a levar em consideração essa pluralidade de valores. Nesse sentido, uma importante tarefa da Comissão de Avaliação foi estimular a análise e reflexão das grandes questões acadêmicas e do próprio processo de avaliação, possibilitando a emergência dessa pluralidade de perspectivas e, dessa forma, o enriquecimento do debate autocrítico. Para essa tarefa de engajar a comunidade e de sustentar um diálogo informado com e entre a comunidade a composição multidisciplinar da Comissão Conjunta CPA/CE foi fator essencial. A presença de especialistas em diferentes áreas (a CPA, inclusive, é estatutariamente composta por especialistas nas três grandes áreas do conhecimento: biológicas, exatas e humanas) possibilitou a criação de um espaço privilegiado de troca de idéias e de negociação, bem como o atendimento às expectativas de diferentes grupos de interesse.

Além disso, a ausência de familiaridade com a teoria e a prática da avaliação, notadamente de uma avaliação democrática e orientada para a auto-gestão, evidenciada em nossa experiência, criou um novo papel para os avaliadores e para a Comissão de Avaliação, o de atuar como um núcleo de apoio, o que envolveu, entre outras funções e atividades: o aconselhamento e orientação em questões conceituais, técnicas e políticas; a produção e socialização de textos para construção de um quadro de referência conceitual; orientações para o processo de sensibilização e para a identificação de objetos, indicadores e descritores qualitativos da avaliação e para o desenvolvimento e uso de metodologias e instrumentos e, inclusive, a proposição de questionários padrão e de esquemas de relatório e sua discussão em oficinas e seminários; treinamento para o acesso, a digitalização e recuperação de dados através do sistema on-line (intranet).

Mas a efetividade dessas ações dependeu, durante todo o processo, do exercício de um outro papel desempenhado pela CPA/CE no período de 2001-2004, o de promotor e articulador de espaços de diálogo e de cooperação, focados no respeito aos princípios e diretrizes democraticamente definidos e aprovados pelas Congregações de todas as Unidades Universitárias para o projeto de avaliação da UNESP. 


\section{Referências}

BRASIL. COMISSÃO PARA A REFORMULAÇÃO DA EDUCAÇÃO SUPERIOR. SECRETARIA DE ENSINO SUPERIOR. MINISTÉRIO DA EDUCAÇÃO. Uma nova política para a educação superior. Brasília, DF: 1985.

\section{Relatório do Grupo Executivo para Reformulação da}

Educação Superior (GERES). Brasília, D.F.: Secretaria de Ensino Superior, Ministério da Educação, 1986.

BRASIL - Lei No. 9394. Estabelece as diretrizes e bases da educação nacional. Diário Oficial da União. 23-12-1996, p.27833 - 27841.

BRASIL. Decreto nº 3860 , de 09 de julho de 2001. Dispõe sobre a organização do ensino superior, a avaliação de cursos e instituições e dá outras providências. Disponível em: http://www.mec.gov.br/legislação. Acesso em: 23 out. 2004.

BRASIL. INSTITUTO NACIONAL DE ESTUDOS E PESQUISAS EDUCACIONAIS. Censo da educação superior 2003. Resumo técnico - tabelas anexo. Disponível em: http://www.inep.mec.gov.br/superior/ censosuperior/relatório_técnico.htm . Acesso em 26 mai. 2007.

BRASIL. INSTITUTO NACIONAL DE ESTUDOS E PESQUISAS EDUCACIONAIS. MINISTÉRIO DA EDUCAÇÃO (MEC). Censo da educação superior 2004. Disponível em: http://www.mec.gov.br/ imprensa/noticias/censo/superior/ Acesso em: 05 dez. 2005.

CRUB. CONSELHO DE REITORES DAS UNIVERSIDADES BRASILEIRAS. Projeto de Avaliação Institucional para as Universidades Brasileiras. Avaliação: Revista da Rede de Avaliação Institucional da Educação Superior-RAIES,Campinas, v. 6, n.1, p. 726, 2001.

DIAS SOBRINHO, José. Avaliação: políticas educacionais e reformas da educação superior. São Paulo: Cortez, 2003. 198p.

DIAS SOBRINHO, José. Educação superior sem fronteiras. Cenários da globalização: bem público, bem público global, comércio transnacional? Avaliação: Revista da Rede de Avaliação Institucional da Educação Superior - RAIES, Campinas, v. 9, n. 2, p. 9-29, jun. 2004.

ELLIOT, John. Changing contexts for educational evaluation: the challenge for methodology. Studies in educational evaluation, Amsterdam, Netherland, v.17, p.215-238, 1991. 
GREGO, Sonia M. D. Avaliação institucional e autonomia universitária. In: TÓVOLI, Emília M.G., SEGATTO, José A.; NOGUEIRA, Marco A. (Orgs.). Gestão universitária. Araraquara: Laboratório Editorial/FCL/ UNESP, 2005. p. 101-120.

GREGO, Sonia M. D. A avaliação institucional dos cursos de graduação: A meta-avaliação como referencial de análise e de reflexão. In:

SGUISSARD, V. (Org.). Avaliação universitária em questão: reformas do estado e da educação superior. Campinas: Autores Associados, 1997. p. 91-122.

Avaliação institucional da UNESP: uma proposta metodológica para a autogestão. Boletim do Departamento de Didática, Araraquara, ano XVI, n. 15, p. 5-42, 1999.

GREGO, Sonia M.D. Perspectivas teórico-metodológicas da avaliação nas Universidades britânicas: subsídios à reflexão. Ensaio: Avaliação e Políticas em Educação, Rio de Janeiro, v. 6, n. 3, p. 29-40, jan./mar. 1995.

KELLS, Herb R. Self-regulation in higher education: a multi-national perspective on collaborative systems of quality assurance and control. London and Philadelphia: Jessica Kingsley Publishers, 1992. 238p.

KEMMIS, Stephen. Seven principles for programme evaluation in curriculum development and innovation. In: HOUSE, Ernest R. (Edit.) New directions in educational evaluation. 2. ed. London and Philadelphia: The Falmer Press, Taylor \& Francis Inc, 1989. p.117-140.

KOGAN, Maurice. The evaluation of higher education: an introductory note. In: KOGAN, Maurice. Evaluating higher education. 2. ed. London: Jessica Kingsley Publisher, 1993. p. 11-25. Higher Education Policy Series, 6.

LEITE, Denise; TUTIKIAN, Jane; HOLZ, Norberto (Orgs.). Avaliação e compromisso: construção e prática da avaliação institucional em uma universidade pública. Porto Alegre: Ed. Universidade/UFRGS, 2000. $237 \mathrm{p}$.

MACDONALD, Barry. Evaluation and the control of education. In: SAFARI PROJECT (Publ.). Inovation, evaluation, research and the problem of control. University of East Anglia: Safari Project, 1974. p. 9-22, 1974. 
MANCEBO, Deise. Autonomia universitária: reformas propostas e resistência cultural. Universidade e Sociedade, Brasília, ano VIII, n. 15, p. 51-59, 1998.

MOROSINI, Marília Costa, LEITE, Denise B. C. Avaliação Institucional como um organizador qualificado: na prática é possível repensar a Universidade? In: SGUISSARI, Valdemar. Avaliação universitária em questão: reformas do Estado e da educação superior. Campinas, São Paulo: Editora Autores Associados, p. 123-148, 1997.

NEAVE, G.; VAN VUGHT, F. A. Prometeo encadenado. Estado y educación superior en Europa. Barcelona: Gedisa, 1994.

OCDE-ORGANIZACIÓN PARA LA COOPERACIÓN Y EL DESARROLLO ECONÓMICOS. Financiamiento de la educación inversiones y rendimientos: Análisis de los indicadores mundiales de la educación. Resumen ejecutivo. França: Ediciones OCDE, Ediciones UNESCO 2002. Instituto de Estadística de la UNESCO.

SHANGAI JIAO TONG UNIVERSITY RANKING. Academic Ranking of World Universities 2006. Top 500 World Universities. Disponível em http://ed.sjtu.edu.cn/rank/2006/ARWY2006.htm Acesso em 23 jan. 2007.

SÃO PAULO. Indicação CEE Nº. 06/99. Avaliação das Instituições de Educação Superior do Sistema Estadual de Ensino. Diário Oficial do Estado, São Paulo, 31 ago. 1999. Seção I, p. 11-12.

SÃO PAULO. Indicação CEE Nº. 04/00 de 23 de março de 2000. Avaliação de universidade e de centro universitário do Sistema de ensino do Estado de São Paulo. Disponível em: http:// www.ceesp.sp.gov.br/. Acesso em: 25 out. 2002.

STUFFLEBEAM, Daniel L. Strategies for institutionalizing evaluation: Revisited. (Occasional Paper Series n.18). Kalamazoo: Western Michigan University Evaluation Center, 1997. . The 21st-Century CIPP Model: Origins, development and use. In: ALKIN, Marvin C. Evaluation roots: tracing theorists' views and influences. Thousand Oaks, London and New Delhi: SAGE Publications, 2004. p.245-266.

STUFFLEBEAM, Daniel L; WEBSTER, W. J. An analysis of alternatives approaches to evaluation. In: MADAUS, George F.; SCRIVEN, Michael. S.; STUFFLEBEAM, Daniel. L. (Ed.). Evaluation 
models: viewpoints on educational and human services evaluation. Boston: Kluwer-Nijhot Publishing, 1991. p. 23-43.

UNIVERSIDADE ESTADUAL PAULISTA. Anuário Estatístico 2005. São Paulo: UNESP, 2005.

UNIVERSIDADE ESTADUAL PAULISTA. Relatório Parcial da Avaliação Institucional: março de 2001 a setembro de 2004.

Comissão Permanente de Avaliação (CPA). UNESP. 291p. Editoração: VUNESP, 2004.

. Projeto de Avaliação Institucional 2001 a 2006. São Paulo:

Comissão Permanente de Avaliação, Universidade Estadual Paulista (UNESP), 2001. 25p.

. Projeto de Avaliação dos Cursos de Graduação 1995 - 1997.

São Paulo: PAIUB, Universidade Estadual Paulista (UNESP), 1995.

Endereço dos autores:

Sonia Maria Duarte Grego

Faculdade de Ciências e Letras / Campus Universitário de Araraquara Depto de Didática

Rodovia Araraquara-Jaú, km 1 - CEP:14800-901

Araraquara, São Paulo

Sheila Zambello de Pinho

Universidade Estadual Paulista

Pró-Reitoria de Graduação

R.Quirino de Andrade, $215-10^{\circ}$. Andar - Centro

CEP:01049-010 - São Paulo, SP

Eunice Oba / José Reinaldo Cerqueira Braz / Hélia Sonia Raphael Faculdade de Medicina Veterinária e Zootecnia, Departamento de Reprodução Animal e Radiologia Veterinária,Unesp,Campus de Botucatu CEP 18618-000 - Botucatu -São Paulo

Maria Cristina Iwama de Mattos

Consultora em Educação na Área da Saúde

Av. Primavera, 60 Vale do Sol-Botucatu

CEP 18607-250 - São Paulo Brasil 